\title{
Religión y política en las elecciones del 2018 Evangélicos mexicanos y el Partido Encuentro Social ${ }^{\star}$
}

\author{
Religion and Politics in the 2018 Elections \\ Evangelical Mexicans and the Social Encounter Party
}

CARLOS GARMA**

\begin{abstract}
The objective is to go in depth into the heterogeneity of the orientations and conducts of evangelical Mexicans towards politics and the diverse positions they exhibit. The variables studied ethnographically(Church, community, personal history and economic situation) regarding each parishioner which affect such orientations. Nevertheless, among the findings we can highlight that there are two common renderings of what affect their political orientation: 1) the notion of politics linked to the earthly, the mundane, the negative; 2) a juarist nationalistic exaltation with input from the anticatholic ideology that is common among evangelical Mexicans. It is concluded that in the 2018 elections, Andres Manuel Lopez Obrador was supported by an evangelical party base and probably this formation could influence some aspects of the new head of state's politics. Key words: Church, political party, Pentecostal, Protestant
\end{abstract}

\section{Prólogo}

$\mathrm{L}$ a población de México se encuentra ante una situación política realmente insólita y nueva, que nadie hubiera podido predecir hace sólo algunos años. Con un amplio margen, Andrés Manuel López Obrador (también conocido como AMLO) resultó vencedor en las elecciones presidenciales del $1^{\circ}$ de julio de 2018 . El presidente electo es identificado como de izquierda y es visto por sus votantes como una alternativa real frente a la continuidad de los que han sido partidos gobernantes durante las últimas décadas. López Obrador obtuvo

\footnotetext{
* Artículo recibido el 16/10/18 y aceptado el 18/12/18.

** Universidad Autónoma Metropolitana, Unidad Iztapalapa, Departamento de Antropología. Av. San Rafael Atlixco núm. 186, col. Vicentina, Iztapalapa, 09340, Ciudad de México <ganc@xanum.uam.mx>.
}

\begin{abstract}
El objetivo es ahondar en la heterogeneidad de las orientaciones y conductas de los evangélicos mexicanos hacia la política y sus diversas posiciones. Etnográficamente se estudia qué variables (Iglesia, localidad, historia personal y situación económica) de cada creyente modifican dichas orientaciones. No obstante, entre los hallazgos destaca que hay dos representaciones comunes que afectan su orientación política: 1) la noción de la política vinculada a lo terrenal, a lo mundano, a lo negativo; 2) la exaltación de un nacionalismo juarista con aportaciones de la ideología anticatólica que es común a todos los evangélicos mexicanos. Se concluye que en las elecciones de 2018, Andrés Manuel López Obrador fue apoyado por un partido de bases evangélicas y probablemente esta formación podrá influenciar algunos aspectos de las políticas del nuevo mandatario. Palabras clave: Iglesia, partidos políticos, pentecostales, protestantes
\end{abstract}


la victoria gracias a que representó a un frente amplio que incluye al primer partido mexicano que de manera abierta expone una orientación y bases evangélicas (en especial pentecostales y neopentecostales): el Partido Encuentro Social (PES), que solía ser considerado por los analistas como de centro derecha.

Al respecto fue ilustrativa la postulación oficial de López Obrador a la Presidencia por el pes el 20 de febrero de 2018. En aquel momento, Hugo Eric Flores, fundador y dirigente de dicha agrupación, utilizó referencias bíblicas para comparar al candidato con figuras del Antiguo Testamento (Rodríguez García, 2018), mientras que López Obrador habló de la necesidad de una nueva constitución moral para cuya elaboración iba a incluir a "filósofos, antropólogos, especialistas, escritores, poetas, activistas, indígenas, líderes de distintas religiones y no creyentes" (Animal Político, 2018). Destacó, además, que esto no se contraponía con la laicidad.

Este artículo se enfocará en explicar cómo se ha pasado de un Estado con una Constitución claramente laica -en una sociedad en la cual los evangélicos eran minoritarios $\mathrm{y}$, en ocasiones, perseguidos- a la coyuntura recién descrita. ${ }^{1}$

En la primera sección del texto se darán algunos datos necesarios para entender el contexto de la religión en México. Se aclararán, asimismo, los términos uti lizados y se proporcionarán datos cuantitativos censales útiles. Después, se señalará el marco histórico y legal de la interacción entre religión y política en México. Luego, se pondrán de relieve distintas concepciones sobre la "política" en las asociaciones evangélicas cristianas protestantes y pentecostales, para mostrar cómo éstas llevan a la aceptación o rechazo de los partidos políticos. Enseguida, se revisará la compleja coyuntura actual, en la que, de manera inédita en la historia del país, hay una intervención general de un partido con una orientación marcadamente influida por las asociaciones evangélicas cristianas, sobre todo pentecostales. Por último, se presentarán algunas conclusiones generales.

\section{Panorama de las Iglesias evangélicas en México}

Las Iglesias protestantes históricas denominacionales tienen sus orígenes directamente vinculados a la Reforma del siglo xvi, inspirada en la obra y pensamiento de Martín Lutero y Juan Calvino. Entre sus Iglesias más importantes en México se encuentran las: presbiteriana, metodista, bautista, luterana, calvinista, la del Nazareno y las congregacionales. Cada asociación religiosa tiene un organismo superior en el ámbito nacional que toma las decisiones más trascendentes y elabora planes y programas de organización (Vázquez, 1991). En estas congregaciones, los pastores suelen tener estudios formales. Entre sus rituales destacan la lectura de la Biblia, fuente única de revelación divina, así como los testimonios de los creyentes (Ruiz, 1992). Desde hace muchas décadas, sus dirigentes y feligresía son mexicanos.

Las Iglesias pentecostales son originarias de Estados Unidos, donde surgieron en 1906, en áreas donde había una fuerte influencia de la población afrodescendiente protestante. El pentecostalismo fue fundado por el pastor afroamericano William Seymour, en la famosa Misión de la Calle Azusa, en Los Ángeles, California (Cox, 1994). Su nombre se deriva de la fiesta cristiana que conmemora el día en que los 12 apóstoles recibieron al Espíritu Santo por primera vez y obtuvieron dones maravillosos como hablar en lenguas, sanar enfermos y profetizar -según el pentecostalismo, todo creyente puede recibir estos "dones" al abrirse al Espíritu Santo-. Entre las agrupaciones pentecostales de mayor envergadura de México están las Asambleas de Dios, la Iglesia Apostólica de la Fe en Cristo Jesús, Iglesia Cristiana Interdenominacional, Centro de Esperanza y Amor, Iglesias Pentecostales Independientes y Amistad Cristiana. En América Latina, entre los evangélicos cristianos predominan los pentecostales, cuyos seguidores suelen venir de sectores populares (Bastian, 1994; Martin, 1990; Cox, 1994). En su mayoría, sus dirigentes y feligresía también son mexicanos.

El término neopentecostal se refiere a Iglesias que tienen bases pentecostales pero que utilizan de manera extensiva los medios de comunicación y suelen orientarse por la llamada teología de la prosperidad, que enfatiza los beneficios materiales para los creyentes. Sus adeptos incluyen no sólo a los sectores populares, sino también a personas de clase media. Su normatividad suele ser más laxa que la practicada en las asociaciones del pentecostalismo clásico. La agrupación que representa mejor esta tendencia es, sin duda, la organización de origen brasileño llamada Iglesia Universal del Reino de Dios, mejor conocida por su popular programa de televisión Pare de Sufrir.

\footnotetext{
1 Una versión preliminar de este trabajo fue elaborada para el proyecto "Evangélicos y poder en América Latina “, coordinado por el doctor Sebastian Grundberger, representante de la Fundación Konrad Adenor Stifung en el Perú, a quien le agradezco el apoyo recibido. Dicho texto será publicado en Lima, Perú, próximamente. Al exponer en diversas conferencias este material y comentarlo con colegas se me pidió que lo publicara en México, por lo cual preparé este texto ampliado.
} 
Sin embargo, en México existen ya otras advocaciones con estas características. Muchas veces están relacionadas con las llamadas megaiglesias de Estados Unidos (Jaimes Martínez, 2007).

Mención aparte merece la Iglesia del Dios Vivo, Columna y Apoyo de la Verdad, La Luz del Mundo, que tiene raíces pentecostales, pero una organización particular que la separa de las otras agrupaciones. Esta institución, fundada en 1926, en Guadalajara, Jalisco, dispone de ciertos recursos económicos y presencia social. Es una asociación de origen mexicano con mucho impacto tanto en el país como en otras partes del continente americano donde habitan migrantes mexicanos y latinoamericanos (De la Torre y Gutiérrez Zúñiga, 2007).

El término evangélico cristiano es utilizado

...por los miembros de todas estas asociaciones religiosas cuando buscan destacar elementos de cohesión y unidad, como las asambleas, reuniones o conciertos musicales patrocinados por varias agrupaciones, así como por alianzas que buscan obtener un fin específico -como la Alianza Cristiana Evangélica por los Derechos Religiosos, por ejemplo-. También usan estas denominaciones para identificarse ante personas desconocidas en vez de dar el nombre de una asociación particular [Garma, 2008: 85].

Cabe señalar que protestantes denominacionales y pentecostales se consideran "hermanos" y enfatizan su distanciamiento del catolicismo como un aspecto vinculante. Para ellos, recibir espíritus ajenos a la divinidad es un pecado grave, lo cual es motivo de condena contra el espiritualismo trinitario mariano, la santería yoruba afrocubana y los movimientos esotéricos que conforman la llamada corriente del new age (De la Torre y Gutiérrez Zúñiga, 2007). El apego de estos grupos evangélicos a una interpretación cuidadosa de la Biblia los separa de mormones (Iglesia de los Santos de los Últimos Días), de los adventistas del Séptimo Día y de los testigos de Jehová, quienes utilizan otros libros sagrados además de la Biblia o apelan a interpretaciones distintivas de dicho texto. En los últimos dos censos, estas tres agrupaciones han sido designadas por el Instituto Nacional de Estadística y Geografía (INEGI) como Iglesias bíblicas no evangélicas. Esta definición se utiliza para señalar que aún tienen una relación con la Biblia; pero ha suscitado confusión en el público no especializado.

Los censos revelan un crecimiento numérico de las Iglesias evangélicas en detrimento de la cantidad de católicos, lo cual ha sido muy visible en las últimas décadas. En 1970, de la población censal, 96.2\% era católica y $1.8 \%$ protestante y evangélica. Sin embargo, ya en $1990,89.7 \%$ se declaraba católica y $4.9 \%$ protestante evangélica. Según el censo de 2010, la población evangélica (protestante, pentecostal y cristiana) en el país sumaba $7.6 \%$ del total de la población. Aunque este porcentaje es significativamente menor que en los otros países centroamericanos, e incluso en la mayoría de los sudamericanos, se calcula que en México hay trece millones de personas que se consideran cristianos evangélicos. Se cree que en el siguiente censo las cifras mostrarán que continuará la tendencia descendiente del catolicismo y el aumento de las otras creencias, incluyendo las asociaciones evangélicas; así como el crecimiento sostenido de quienes se declaran no creyentes (INEGI, 2018).

Es importante señalar que hay diferencias regionales considerables. Así, en 2010, en Chiapas, entidad localizada en la frontera sur del país, la población católica sólo era de 58.3\% (la más baja en México); la evangélica protestante de 19.2\%; los bíblicos no evangélicos representaron $8.5 \%$ de la población y los no creyentes y otras religiones $14 \%$. Otras entidades federativas del sur del país -como Tabasco, Quintana Roo, Campeche y Veracruz- mostraron porcentajes más bajos que el promedio nacional en cuanto al número de católicos (entre 65 y 75\%) y un porcentaje más alto de evangélicos protestantes ( 12 a 18\%). Una explicación para esta tendencia es la conversión de indígenas, campesinos y migrantes a las denominaciones no católicas, que tienen mucha influencia en estas regiones. En contraste, las entidades federativas del centro oeste -como Aguascalientes, Jalisco, Zacatecas, Querétaro y Guanajuato- tienen poblaciones más urbanas con una orientación cultural más ibérica y son casi completamente católicas. Así, en 2010, los católicos representaban en Guanajuato 93.8\% de sus habitantes, y los evangélicos protestantes sólo $2.5 \%$. La Ciudad de México, capital del país, tiene una situación intermedia, aunque algo compleja. Los católicos concentran $82.4 \%$ de la población; los protestantes evangélicos 5.3\%; y los bíblicos no evangélicos 1.3\%. Por su parte, la categoría "sin religión” obtuvo aquí una presencia significativa de 5.4\% (Garma y Leiva, 2015: 101; INEGI, 2018).

\section{Religión y política en México desde el marco histórico y legal}

Durante el periodo colonial en la Nueva España prevalecieron estrechos vínculos entre la Corona imperial hispánica y la Iglesia católica, expresados en el Real Patronato establecido en 1501 entre el Vaticano y la Corona española. Debido a dicho acuerdo, la única 
religión permitida en la Nueva España era la fe católica. Por tanto, las religiosidades indígenas, el judaísmo y la "herejía luterana" estaban prohibidos (Bastian, 1983). Al cristalizarse la Independencia de México en 1821 se perdieron las relaciones directas con el Vaticano. Años después se vivieron fuertes luchas entre liberales y conservadores, que fueron alentadas por el problema de la separación entre un Estado reciente y una Iglesia católica dominante. Con el tiempo, por convenirle al gobierno, se buscó la dominación legal de las instituciones religiosas. La victoria liberal culminó con la presidencia de Benito Juárez, quien todavía es una figura de referencia para los evangélicos en este país. Juárez estableció la separación de Iglesia y Estado en 1857, con lo cual dio paso al primer Estado laico estable en América Latina (Galeana, 2001). Dicha legislación permitió la institucionalización de las primeras Iglesias protestantes en el país, recién fundadas en ciudades norteñas como Monterrey (Scott, 1991).

Aunque durante el largo periodo de gobierno de Porfirio Díaz (1876-1880, 1884-1911) el Estado fue tolerante con la Iglesia católica, a partir de los gobiernos surgidos de la Revolución de 1910 dicha institución volvió a ser considerada un adversario reaccionario que buscaba el retorno de posiciones conservadoras. La Constitución de 1917 estableció una normatividad excesivamente restringida en materia religiosa, de modo que las asociaciones religiosas no tenían reconocimiento legal o jurídico, ni podían tener posesiones o dirigir escuelas. En este contexto, las ceremonias religiosas públicas no eran permitidas y los ministros de culto no podían votar ni involucrarse en actividades políticas. Estos elementos legales tan severos no se podían aplicar sin causar serios conflictos sociales (Blancarte, 1992; Meyer, 1989). Esto se evidenció en la Guerra Cristera que tuvo lugar de 1926 a 1929 y que afectó a una parte importante del país. Este suceso derivó en una situación en la cual se aplicaba una legislación identificada en la esfera internacional como de un anticlericalismo extremo (puesto que ni siquiera reconocía legalmente a las Iglesias, no les permitía tener propiedad alguna y limitaba con severidad los derechos de los líderes de culto). Asimismo, se definía al país como una república laica y estaban prohibidos los partidos confesionales. Estas disposiciones afectaron, sobre todo, a la Iglesia católica, debido a que era la institución eclesial mayoritaria; pero, en una escala mucho menor, también repercutieron en las Iglesias protestantes (Garma, 2007).
Aunque esta etapa anticlerical duró varias décadas, con el tiempo se fue modificando. La situación jurídica hoy es muy distinta. La Ley de Asociaciones Religiosas y Culto Público, aprobada en julio de 1992, durante el gobierno de Carlos Salinas de Gortari, instituye un marco legal para normar las relaciones entre el Estado y las Iglesias, e instaura formalmente la relación entre ellos a partir de dicha fecha. Vale precisar que no establece un reconocimiento laxo o endeble, pues exige el registro oficial como asociación religiosa para reconocer de forma legal a las colectividades de creyentes. Todas las Iglesias deben cumplir con este requisito y no hay distinción entre ellas para tal efecto. Así, la Iglesia católica apostólica romana también está registrada, tanto por diócesis como por sus órdenes religiosas, cada una de las cuales tiene un registro particular. Esta medida exige que las agrupaciones cumplan con los requisitos que la ley fija para ser una asociación religiosa. La legislación las obliga, asimismo, a que no afecten los derechos individuales de las personas en su integridad física y moral ni en lo concerniente al derecho a la libertad de credo. Los ministros de culto ya son reconocidos oficialmente por el Estado, así como las propiedades y bienes que se requiriesen para llevar a cabo los servicios, ceremonias y rituales.

Cabe añadir que la responsabilidad de hacer cumplir la ley no recae en las cortes, sino en la Secretaría de Gobernación, a la cual pertenece la Subsecretaría de Población, Migración y Asuntos Religiosos. La ley mexicana sí precisa cierto grado de control por parte del Estado sobre las asociaciones religiosas en general, pero éste debe circunscribirse a lo estrictamente necesario para no infringir el derecho a la libertad de credo. Debemos señalar que algunas limitaciones se mantuvieron. Por ejemplo, los ministros de culto aún no pueden tener cargos políticos ni ser elegidos para puestos populares y las Iglesias tampoco pueden ser dueñas de medios de comunicación (Garma, 2010). ${ }^{2}$ En la actualidad, han obtenido su registro legal más de 8000 asociaciones religiosas (INEGI, 2018).

\section{El problema de la política}

Las actitudes de los protestantes y pentecostales hacia lo que denominan "la política" pueden ubicarse en diferentes concepciones. Para algunos de ellos, la política está vinculada a la vida terrenal y a las cosas del mundo, al aquí y el ahora. Según este enfoque, poco o nada tiene que ver la política con las cosas sagradas

\footnotetext{
2 Ley de Asociaciones Religiosas y Culto Público (17 de diciembre de 2015) <http://www.diputados.gob.mx/LeyesBiblio/
} pdf/24_171215.pdf>. 
o divinas, con las preocupaciones espirituales o del alma, de modo que el contacto con la política ensucia, contagia y lleva a la maldad. El oficio del político, entonces, está ligado a la corrupción, al culto al dinero y al poder; no a Dios. "No se puede servir a dos amos", dicen con convicción aquellas personas que sostienen esta orientación hacia la búsqueda de puestos de influencia y control. Así lo expresan también aquellos conversos que han dejado atrás su militancia política para dedicarse a una nueva vida religiosa. Desde este punto de vista, es imposible imaginar que la política pueda reformarse o redimirse como forma de vida (Garma, 2004; Scott, 1991).

Sin embargo, existe otra posición que afirma que los creyentes pueden dedicarse a la política y seguir siendo personas morales y religiosas. Los evangélicos que suscriben esta postura (apelando a varios aspectos protestantes reconocidos) consideran que el problema con el país es que la política se ha dejado precisamente a los corruptos y a los inmorales, quienes han pervertido a las instituciones del gobierno para su propio lucro. En este punto, es importante la concepción de que el buen creyente debe predicar con el ejemplo, ya que el hombre religioso debe ser como una "luz que alumbra la oscuridad", del modo en que lo indica una metáfora bíblica muy difundida. De esta manera, el buen ejemplo de un político evangélico podría servir para reformar una institución social enferma. En suma, esta orientación puede combinarse bien con una posición nacionalista -están los casos de Benito Juárez y los hombres de la Reforma mexicana- (Garma, 2004; Scott, 1991).

Además, hay una tercera posición intermedia, según la cual el ejercicio de una actividad política podría justificarse de acuerdo con circunstancias muy específicas, pongamos por muestra si la congregación y sus creyentes estuvieran en peligro, pues no se tendría otra opción y la pasividad política sería desastrosa. Para los protestantes y evangélicos mexicanos esta coyuntura se relacionaba con circunstancias de intolerancia y persecución ocurridas en contextos muy puntuales, como fueron las expulsiones masivas de creyentes evangélicos de 1970 a 1990 en la comunidad tzotzil de San Juan Chamula, localizada en los Altos de Chiapas (Garma, 2004; Scott, 1991).

Es pertinente señalar que un rechazo a la vida política no implica necesariamente rehusar sus instituciones. El creyente puede desconfiar de los políticos, pero esto no supone que no debe votar o cumplir sus obligaciones en cuanto ciudadano. En efecto, rechazar las instituciones políticas en su totalidad sería adoptar la posición de los testigos de Jehová, que no saludan a la bandera, no cumplen el servicio militar y, desde su perspectiva, tampoco deben votar. Los protestantes y pentecostales más diversos siempre reaccionan destacando que ésta no es su postura. Como ya se ha indicado, hay un apego al juarismo nacionalista y a sus símbolos -como llamar a Juárez el "Benemérito de las Américas”-, así como a las referencias al proceso de la Reforma mexicana. Pero, a la vez, se menciona que Benito Juárez no fue igual que los políticos actuales, pues se argumenta que era un hombre cabal e íntegro, por lo menos así se le describe en este tipo de discurso. No obstante, los mismos evangélicos y pentecostales que desconfían de los políticos de hoy en día acuden a los actos cívico-religiosos que celebran anualmente el natalicio de Juárez el 21 de marzo en la Alameda Central de la Ciudad de México y en diversos puntos del país (Garma, 2004; Garma y Méndez, 2012; Scott, 1991).

Así pues, siguiendo el espíritu juarista, se defiende el ideal de una separación completa y absoluta de la Iglesia y el Estado. Este tópico alude a la frase bíblica atribuida a Jesucristo de "Dad al César lo que es del César y a Dios lo que es de Dios" (Lucas 20: 25). Desde esta perspectiva, el Divino Salvador y el Benemérito de las Américas podrían darse la mano y estar en absoluto acuerdo.

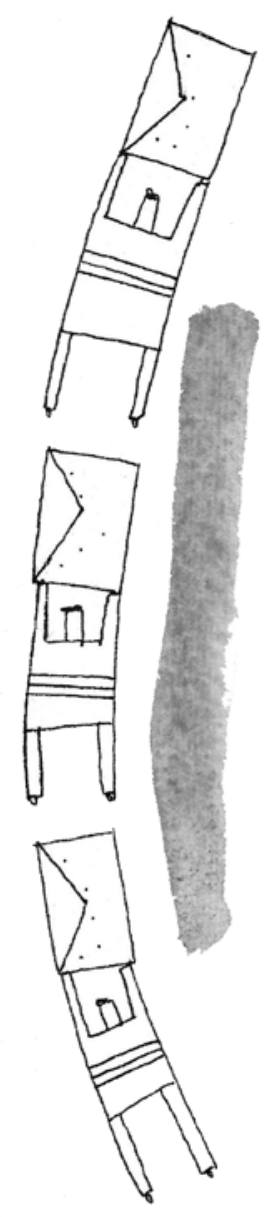


Por otra parte, diferentes partes de la Biblia son utilizadas tanto por las personas que defienden la pasividad política como por los que proponen el activismo. Así, para quienes sostienen la pasividad política es indispensable recordar la epístola de Pablo a los romanos (13: 1-14) en donde el apóstol destacaba la obediencia a las autoridades civiles como parte de la voluntad divina. Recuérdese, después de todo, que Pablo era un ciudadano romano y, aunque esto no fue suficiente para evitar su martirio, dicha condición sí le concedió un estatus diferente respecto a los demás apóstoles y evangelizadores, lo que en determinados momentos de su vida le fue ventajoso (Dussel, 1977).

En cambio, aquellos que proponen el activismo político acostumbran citar las acciones de los profetas del Antiguo Testamento que cuestionaban el orden político injusto que sojuzgaba al pueblo hebreo durante los años de su dominación colonial por potencias imperiales extranjeras. Estos pasajes también suelen ser los que citan los teólogos de la liberación católicos, algo que preocupa a algunos autores y dirigentes evangélicos que desconfían de una alianza con sectores de la institución religiosa dominante (Dussel, 1977).

En todo caso, es claro que la misma fuente -la Biblia- puede ser utilizada para propósitos muy distintos, como ha sido destacado muchas veces por especialistas y autores muy diversos (Douglas, 2006; Dussel, 1977; Pitt-Rivers, 1977).

La Encuesta Nacional de Creencias y Prácticas en México Encreer/Rifrem, que fue realizada del 29 de octubre al 30 de noviembre de 2016, nos da algunos datos adicionales. Los evangélicos encuestados en diferentes partes del país mostraron un apoyo mayoritario a la separación Estado-Iglesia. Por lo que toca a la pregunta "Está usted de acuerdo en que las religiones participen abiertamente en política electoral”, sólo $24 \%$ de los evangélicos respondió afirmativamente. De manera más contundente, en relación con la pregunta "Está usted de acuerdo en que los candidatos a elección popular usen los símbolos o recursos religiosos para ganar votos”, sólo 9\% contestó que sí. Esto muestra con claridad una orientación hacia la laicidad, por lo menos en este tema (Rifrem, 2017: 59).

\section{Aceptación o rechazo de los partidos políticos}

Existen diversas publicaciones sobre la orientación electoral de los evangélicos en América Latina y en particular sobre los partidos políticos evangélicos que en algunos países como Perú, Brasil y Guatemala tienen cierto impacto (Bastian, 1999; Da Costa, 2004;
Martin, 1990). Ortega Gómez señala que: "Los partidos políticos evangélicos son organizaciones políticas cuya formación responde a la decisión de un grupo de personas con una identidad religiosa, sean pastores o laicos, que determinen la creación de la organización partidista como mecanismo de sus intereses particulares" (2018: 438). En México, la aparición de un partido político evangélico es reciente. Esto se debe a los factores históricos y sociales antes mencionados y también a las orientaciones que a continuación expondremos.

Los protestantes históricos y pentecostales en México suelen converger en sus orientaciones e inclinaciones partidarias. Hay variaciones de un templo a otro, pero esto se debe a las diferencias entre la membresía de una congregación respecto de otra. Puede haber más de una tendencia según la composición de una congregación conforme a su clase social, escolaridad y proporción de los géneros entre los miembros de las Iglesias. Pero los evangélicos mexicanos, en general, sí comparten elementos en su orientación hacia el problema del gobierno, y por ello muchos elementos son comunes. Para empezar, al escoger un partido los creyentes evangélicos no pueden dejar de lado su orientación religiosa. La opción partidista considera los valores religiosos, si bien éstos no actúan en el vacío, sino en combinación con otros factores. Lo anterior no implica que un líder religioso pueda decirle a un creyente por quién votar e influir directamente en las elecciones. No obstante, puede fomentar que la congregación sufrague teniendo en cuenta sus principios religiosos, algo que sí sucede con frecuencia. Sin duda, los miembros de una Iglesia pueden ser influidos por la orientación del pastor o líder religioso, pero hay otros elementos que también inciden en una orientación específica (Cervantes-Ortiz, 2015).

Los protestantes y pentecostales casi siempre se interesan por la política y por las elecciones, incluso cuando están influidos por la valorización que su religión y credo tienen hacia las actividades "de este mundo", que se expresa en una tremenda desconfianza hacia el ejercicio de los puestos civiles del poder. Pero también repercute en los creyentes protestantes y pentecostales el contexto social donde se desenvuelven.

Tradicionalmente, muchos miembros de las minorías religiosas han considerado que el partido oficial, el Partido Revolucionario Institucional (PRI), es el auténtico heredero de la tradición laica y nacionalista del país. Como producto oficialista de la Revolución mexicana, no pocos políticos y representantes príistas defendían los principios nacionalistas sustentados en la subordinación de la Iglesia católica frente al Estado. Durante muchos años, el Estado mexicano se presentó como una institución que defendía la libertad 
de culto y credo, así como el baluarte de educación laica no religiosa. En estas circunstancias, el PRI fue considerado un pilar del Estado nacionalista y juarista dada la separación Estado-Iglesia que se mantuvo en México durante décadas (Garma, 2004; Scott, 1991).

Hay, pues, una profunda desconfianza de los fieles de religiones minoritarias, entre ellas las evangélicas, hacia el Partido Acción Nacional (PAN), de centro derecha, debido a que históricamente mantiene vínculos cercanos con la Iglesia católica y a que su ideología partidista está influenciada por esta institución. En general, los creyentes protestantes y pentecostales sostienen que una alianza con este partido sería con la Iglesia católica romana que, casi siempre, los ha perjudicado. Cabe señalar que algunas asociaciones neopentecostales, como Casa sobre la Roca, se han aliado con algunos políticos del PAN, en particular con el expresidente Felipe Calderón, pero se recela mucho de este tipo de relaciones (Garma, 2004; CervantesOrtiz, 2018).

Entretanto, gran número de evangélicos veía con buenos ojos al Partido de la Revolución Democrática (PRD), que hasta hace poco se denominaba de izquierda. Sus fundadores destacaron la herencia de la orientación nacionalista de la laicidad y tolerancia del cardenismo mexicano, que se plasmaba en la figura de Cuauhtémoc Cárdenas, hijo de Lázaro Cárdenas. La izquierda mexicana supo congraciarse con un sinfín de miembros de las minorías religiosas a pesar de su orientación socialista, por la defensa de los principios del secularismo y del respeto a la diversidad, así como por la orientación juarista de gran parte de sus representantes; pero, posteriormente, la izquierda mexicana se fracturó como consecuencia de la formación del partido Movimiento de Regeneración Nacional (Morena).

En suma, respecto a lo descrito en este acápite, otra opción para los evangélicos sería formar un nuevo partido político sobre lo que se ha llamado "bases evangélicas", con un liderazgo evangélico y guiado por lineamientos de acción trazados por los propios evangélicos. Para los defensores de esta propuesta, el político evangélico debe ser una persona con una elevada moralidad y que actúe conforme a los preceptos cristianos y bíblicos, que han estado ausentes en el escenario político nacional. Esta alternativa no había fructificado dado que la Constitución mexicana prohibía los partidos religiosos oficiales. Sin embargo, desde
1992, la legislación se fue abriendo cada vez más a la participación política de las agrupaciones religiosas. Es curioso que hayan sido las administraciones de los presidentes conservadores Vicente Fox y Felipe Calderón, del PAN, las que generaron espacios en la arena política para las asociaciones religiosas (Garma, 2011).

\section{Evangélicos en la coyuntura política actual}

En 2006 se constituyó el Partido Encuentro Social (PES), fundado en el estado de Baja California, en un principio como asociación civil con afinidades electivas (Weber, 1983), con agrupaciones neopentecostales, pero sin ser abiertamente un partido confesional, puesto que la prohibición constitucional sobre éstos no se ha derogado. El pes fue fundado por el abogado y catedrático cristiano Hugo Eric Flores, quien nació y creció en una familia evangélica perteneciente a la Iglesia de Dios; estudió en la Universidad Nacional Autónoma de México y en la Universidad de Harvard. Posteriormente mantuvo fuertes vínculos con una Iglesia neopentecostal llamada Casa sobre la Roca, conocida por las actividades de sus dirigentes (los esposos Alejandro y Rosa María Orozco) en el sector público durante la Presidencia de Felipe Calderón (2006-2012), periodo en el cual ambos ocuparon posiciones importantes (Barranco, 2011; Patiño Reséndiz, 2016). ${ }^{3}$

Antes de fundar el PEs, Hugo Eric Flores participó en diversas agrupaciones políticas de tendencias y orientaciones muy distintas; incluso en 2006 (a principios del gobierno calderonista) llegó a ser, durante seis meses, oficial mayor de la Secretaría de Medio Ambiente y Recursos Naturales (Barba, 2018).

En julio de 2014, Encuentro Social obtuvo su registro oficial como partido político nacional (Barranco, 2014). Ha logrado cierta presencia en algunas partes del país y es conocido por el apoyo que ha obtenido de creyentes, sobre todo de Iglesias neopentecostales y pentecostales clásicas. Ha postulado con frecuencia a fieles evangélicos, aunque ha evitado que sean ministros o pastores activos. Incluso, la fonética del nombre PEs hace clara alusión a un símbolo bíblico comprendido ampliamente por los creyentes. Como ha señalado un articulista muy conocedor de los sectores protestantes:

3 Alejandro Orozco fue director del Instituto Nacional Para Adultos Mayores (Inapam) de 2007 a 2009 . Actualmente es dirigente de Casa sobre la Roca. Por su parte, Rosa María Orozco fue diputada federal del pan de 2009 a 2012 , lapso en el que presidió la Comisión Especial de la Lucha contra la Trata de Personas. Sigue siendo columnista invitada del periódico Milenio, es una activista en favor de los derechos de las mujeres y dirige una fundación contra la trata de personas (Patiño Reséndiz, 2016). 
lo anterior no significa que el nuevo partido político haya dejado de lado los electores que no son protestantes evangélicos, sino que la mayor parte de sus recursos y fuerzas se están enfocando al convencimiento del pueblo evangélico para que apoye a los suyos [Martínez García, 2015].

El presidente actual del partido sigue siendo Hugo Eric Flores, quien también se desempeñó como diputado federal de la LXIII Legislatura del Congreso mexicano (2015-2018). Su liderazgo personal sobre el partido con frecuencia es comparado con el de un ministro o pastor frente a una congregación (Barba, 2018; Cervantes-Ortiz, 2018).

La orientación ideológica del pes es muy singular. El partido ha sido acusado a menudo de ser oportunista debido a que ha hecho alianzas con grupos muy disímiles. También ha apoyado movilizaciones masivas contra la aprobación del matrimonio igualitario junto con organizaciones de la derecha católica, lo cual fue novedoso, pues en el transcurso de la historia estas agrupaciones se habían considerado enemigas acérrimas de las agrupaciones evangélicas en México. Fue así que el PEs participó (al lado de varias agrupaciones protestantes denominacionales y pentecostales) en dos marchas masivas, llevadas a cabo el $10 \mathrm{y}$ el 24 de septiembre de 2016, junto con la conservadora agrupación católica llamada Frente Nacional por la Familia, contra la iniciativa del presidente Enrique Peña Nieto de legalizar el matrimonio igualitario en todo el país y permitir la adopción de menores por parejas no heterosexuales, propuesta por el Ejecutivo el 17 de mayo de ese mismo año (Romero Puga, 2018). ${ }^{4}$ Además, el pes ha criticado todo intento por legalizar drogas. Asimismo, sus militantes han alertado contra lo que denominan "la ideología de género" en el ámbito público y, en particular, en el espacio educativo. Destaca su defensa de lo que llaman la familia "natural": exclusivamente la heterosexual. Al respecto, de manera crítica, algunos especialistas han afirmado que los miembros de Encuentro Social son evangélicos que han pasado de ser discriminados a ser discriminadores (Blancarte, 2016).

En su página de internet, el pes se define sin disimulo como el partido de la familia tradicional mexicana, que tiene como una de sus metas la defensa de los valores éticos. Señalan allí que son "liberales en asuntos económicos y son sociales en temas de igualdad y de clase", por lo cual promueven un nuevo pacto general para el país. Se destaca que la agrupación se propone ser "la voz de los sin voz", y por ello va a "luchar contra la desigualdad y ayudar a los vulnerables". Podemos notar que estos postulados tan poco precisos pueden adaptarse a posiciones políticas muy diversas. El PEs está organizado por movimientos sectoriales que abarcan los siguientes grupos: campesinos, obreros, empresarios, migrantes, personas con discapacidad, jóvenes, mujeres, adultos mayores y familias. Así pues, las semejanzas con la estructura de los ministerios de una asociación de creencia evangélica son muy evidentes. Sin duda, una de sus fortalezas es su capacidad de llegar a tener influencia en un mosaico muy variado de la sociedad nacional, otra característica de las Iglesias pentecostales (Bastian, 1994).

Sin embargo, para las elecciones de 2018, el PEs se alió no con el PRI ni con el PAN, sino con Morena, del líder izquierdista Andrés Manuel López Obrador, en la coalición Juntos Haremos Historia. López Obrador, connotado político de origen tabasqueño, fue jefe de Gobierno de la Ciudad de México de 2000 a 2005 y, en dos ocasiones anteriores (2006 y 2012), candidato presidencial, antes de ser electo presidente en 2018 con $53.2 \%$ de los votos.

Existe una gran preocupación en algunos sectores de la izquierda por la alianza del PEs con Morena y AMLO, sobre todo por la posición del pes en lo referente a la llamada "agenda moral", que incluye los derechos de los grupos de diversidad sexual y el aborto. La posición tradicional de la izquierda mexicana ha sido la defensa de los derechos de la diversidad sexual -con énfasis en los grupos LGBT- y de la interrupción legal del embarazo. No obstante Andrés Manuel López Obrador ha sido cauto con estas cuestiones, ha puntualizado que no se deben perder los derechos conquistados (sobre todo en la Ciudad de México), pero que desea realizar consultas públicas sobre estos asuntos. Esta posición es considerada por algunos comentaristas como una concesión inaceptable (Blancarte, 2018; Barba, 2018), pero, en razón del amplio apoyo popular del que goza AMLO, este tema no resulta vital para muchas personas.

Mientras la coalición de López Obrador logró obtener las mayorías en el Senado y en la Cámara de Diputados, los resultados del PEs no fueron tan favorables. En el Senado este partido obtuvo $2.42 \%$ de los votos del total y 7 de 128 senadores. En la elección para diputados federales tuvo $2.5 \%$ y 55 de 500 diputados. En consecuencia, al no obtener 3\% en ninguna categoría, perdió su registro oficial como partido. El Instituto Nacional Electoral adoptó una postura muy

\footnotetext{
4 Cabe señalar que, después de las marchas, la propuesta fue retirada el 9 de noviembre de 2016 por los mismos grupos que la propusieron ante la Cámara de Diputados.
} 
estricta al respecto y no aceptó las reclamaciones del PEs en referencia a un posible error de conteo. El 3 de agosto de 2018, el Tribunal Electoral del Poder Judicial de la Federación desechó los argumentos del PEs de una apelación final de recuento y la suerte del partido quedó sellada. Perdía, así, su registro, a pesar del triunfo de su candidato presidencial. Este acuerdo fue oficializado el 8 de julio del mismo año.

¿Qué pasó entonces? El PEs no obtuvo votos suficientes, aunque AMLO sí y su partido Morena arrasó. Asimismo, los evangélicos votaron en gran medida por AMLO, pero no por el PES; las boletas electorales sí permitían el voto diferenciado. La derrota de Hugo Eric Flores y el PES ocurrió por varios elementos. Por una parte, los evangélicos cristianos mexicanos mantuvieron su diversidad de posiciones y muchos no reconocieron al PES ni a su líder omnipresente como representantes legítimos de la comunidad de creyentes (Masferrer, 2018). Esto es más que evidente. El atractivo recayó en AMLO como líder carismático, pero este factor no se replicó en el PEs. Es preciso destacar que hay votantes evangélicos que siguen apoyando el Estado laico y desconfían de un partido con bases religiosas. En este sentido, siguen siendo a todas luces "juaristas".

Por otro lado, las instancias electorales del Estado mexicano actuaron de modo muy riguroso contra las apelaciones del PEs. Ni el Instituto Nacional Electoral ni el Tribunal Electoral del Poder Judicial de la Federación deseaban avalar un partido con bases religiosas activas. Con ello se pone de manifiesto la defensa de

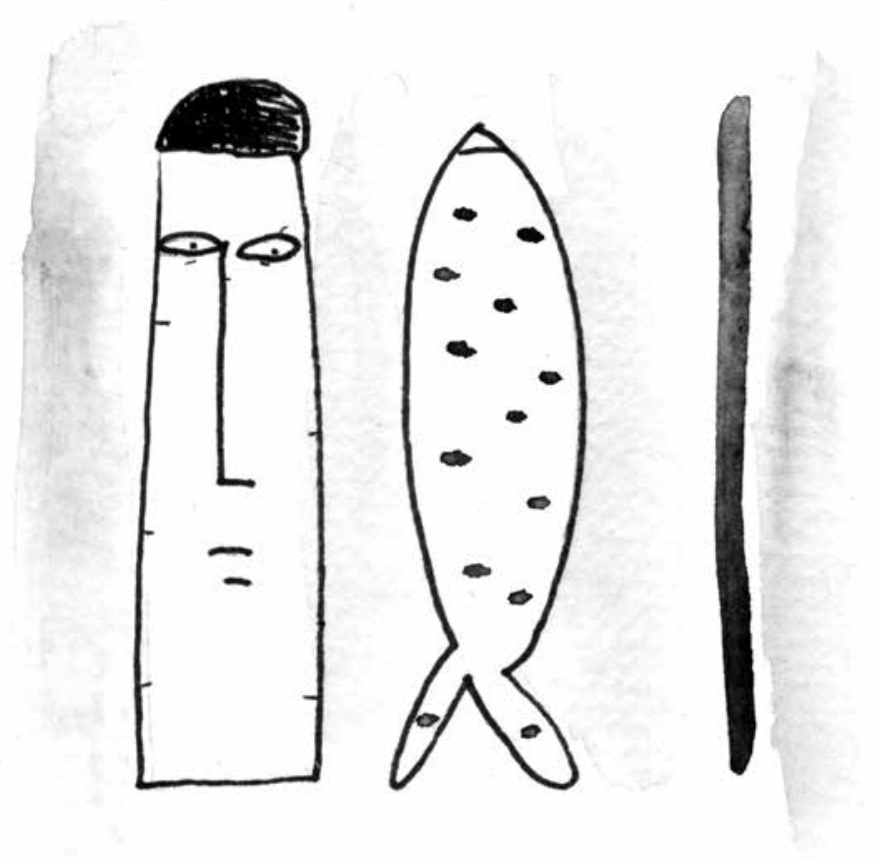

un Estado laico fuerte y cerrado. Además, la situación de otros países de América Latina sirvió como ejemplo de lo que podría suceder si se reconocía al PEs.

Cabe mencionar que López Obrador tampoco defendió al PEs y se mantuvo con la victoria de Morena. Sus nombramientos para el gobierno han recaído en la izquierda mexicana más tradicional, orientada al nacionalismo y al cambio social, y centrada en la defensa de los derechos humanos de todo tipo. En efecto, miembros de su gabinete defienden el matrimonio igualitario y la legalización del aborto.

Gracias a su alianza con López Obrador, y a pesar de su modesta participación electoral, el PEs obtuvo 55 diputados y 7 senadores electos; no obstante, sin un partido de respaldo, pasan a ser independientes. Al perder su registro legal, el PEs también queda sin financiamiento. En este escenario, es probable que los diputados de esta agrupación se unan a otros grupos del Congreso, ya sea por sus intereses de clase o sociales, pero por no tener un partido político propio no pueden dirigir ninguna comisión. Sin embargo, son importantes para garantizar la mayoría de la coalición gobernante en ambas cámaras.

Lo que parece incontestable es que México aún no está en condiciones de tener un partido evangélico vigoroso. Todavía está por verse si el PEs puede reorganizarse, pero en el escenario actual las diferencias entre los evangélicos cristianos mexicanos fueron demasiado fuertes para mantener un proyecto electoral nacional común. Los resultados hablan por sí mismos.

Mucho se ha especulado sobre si el presidente electo López Obrador tiene una filiación religiosa específica. Él ha manifestado su admiración hacia Benito Juárez, de quien destaca su influencia ideológica, por lo cual ha señalado que la religión de los políticos es un asunto privado (Hernández Borbolla, 2018). Debido a que es originario de Tabasco, donde el protestantismo tiene cierta fuerza, la posibilidad de la influencia evangélica es factible. Sobre este punto, un periodista afirma que López Obrador fue socializado dentro del Adventismo del Séptimo Día. Al respecto, el sociólogo Bernardo Barranco apunta:

En este proceso electoral, el candidato que más ha utilizado las metáforas religiosas ha sido Andrés Manuel López Obrador, quien, de manera reiterada sostiene: "cuando me preguntan de qué religión soy, digo que soy cristiano, en el sentido más amplio de la palabra, porque Cristo es amor y la justicia es amor" [Barranco, 2018a].

Para algunos, López Obrador podría ser considerado formalmente como el primer presidente evangélico de México. No obstante, ha cuidado de guardar una 
deliberada ambigüedad en su identidad religiosa. Su movimiento se llama Morena en alusión a la Virgen de Guadalupe, quien es conocida comola "Virgen Morena", y la promulgación de su candidatura presidencial la inició precisamente el 12 de diciembre, cuando se le conmemora. Durante la ceremonia de su investidura, Andrés Manuel López Obrador participó en una ceremonia de entrega de bastón de mando supuestamente indígena, pero contenía muchos más elementos de la llamada espiritualidad new age (Barranco, 2018b).

\section{Conclusiones}

Las orientaciones y conductas de los evangélicos mexicanos hacia la política no son uniformes. En consecuencia, no hay una cultura política unificada de protestantes y pentecostales mexicanos, sino diversas posiciones que pueden variar según la Iglesia, la localidad, la historia personal y la situación económica de cada creyente. Por tal razón, es difícil esperar un éxito seguro de un partido -o "bancada"- evangélico uniforme (Garma, 2004; Cervantes-Ortiz, 2018; Scott, 1991). En suma, sólo se pueden presentar tendencias generales.

No obstante, hay representaciones comunes que afectan la orientación política de los creyentes. Una es la noción de la política vinculada a lo terrenal, a lo mundano, a lo negativo. La otra es la exaltación de un nacionalismo juarista con aportaciones de la ideología anticatólica que es común a todos los evangélicos mexicanos. Hay diversas maneras de unir ambas representaciones y habría, incluso, creyentes más dispuestos a resaltar más una que la otra. Si aceptamos la cultura política como "el conjunto de signos y símbolos que afectan a las estructuras de poder de una unidad operante en cualquier nivel de integración social local, provincial, estatal, nacional o internacional, mundial" (Varela, 1996: 149), podemos señalar que los evangélicos tienen elementos simbólicos enfocados en lo que llaman la política y el gobierno. Sin embargo, aún no podría considerarse que haya suficientes puntos de unión entre los fieles de las distintas Iglesias para hablar de una cultura política evangélica en México, lo que hay, en cambio, es una diversidad de representaciones y orientaciones influidas por la situación religiosa. Pero eso no es todo, esta diversidad se presenta no sólo en el conjunto de asociaciones religiosas protestantes y pentecostales sino también, como han demostrado diversos autores, en el interior de las mismas Iglesias y congregaciones (Garma, 2004; Cervantes-Ortiz, 2015). Esto permite entender por qué la propuesta de un partido evangé- lico que representaba el conjunto del sector estaba destinada al fracaso.

Un problema interesante sigue siendo la aceptación de todos los grupos sociales minoritarios, tanto de las minorías religiosas como, entre otros, los grupos de la diversidad sexual. La percepción social de algunos representantes evangélicos como intolerantes sin duda erosionó el apoyo a organizaciones como el PEs ante sectores estatales y de la sociedad civil. Podemos señalar que la diversidad religiosa es esencial para la sociedad pluralista y multicultural, porque promueve la tolerancia mediante la aceptación social de las minorías sociales como sujetos dignos de respeto no obstante sus diferencias con las mayorías. En efecto, aceptar la heterogeneidad es básico para la construcción de una auténtica colectividad social moderna. $\mathrm{El}$ reconocimiento de los derechos de las religiones y colectividades minoritarias permite avances que afectan todo el campo religioso y la vida social en general. Así, no sólo son considerados los derechos de las mayorías, sino que el trato a las minorías propicia un reconocimiento democrático y equitativo para todos. $\mathrm{El}$ problema no es la tolerancia hacia los semejantes, sino hacia aquellos que no lo son o que incluso no aceptan las mismas reglas de interacción con los demás.

\section{Fuentes}

Animal Político

2018 "López Obrador propone lograr crear una constitución moral y crear un diálogo interreligioso en el país”, en Animal Político, 20 de febrero <https: / /www.animalpolitico.com/2018/02/ amlo-propone-constitucion-moral/ > [ 7 de enero de 2019].

BARBA, SANDRA

2018 "La derecha nos rebasa por la izquierda", en Letras Libres, núm. 233, pp. 24-26.

BARRANCO, BERNARDO

2011 "Casa sobre la Roca, la nueva derecha neopentecostal", en La Jornada, 12 de octubre <https: / / www.jornada.com.mx/2011/10/12/ opinion/021a1pol> [7 de enero de 2019].

BARRANCO, BERnARDo

2014 "El nuevo partido neopentecostal", en La Jornada, 30 de julio <https://www.jornada. com.mx/2014/07/30/politica/022alpol> [7 de enero de 2019].

BARRANCO, BERNARDO

2018a "López Obrador, el candidato de Dios", en La Jornada, 30 de mayo <https: / /www.jornada. com.mx/2018/05/30/opinion/019a2pol> [7 de enero de 2019].

BARRANCO, BERNARDO

2018b “AмLO, su nueva simbología”, en Milenio Diario, 5 de diciembre <https://www.milenio. com/opinion/bernardo-barranco/posteando/ amlo-su-nueva-simbologia> $[7$ de enero de 2019]. 
Bastian, JeAn-PierRe

1983 Protestantismo y sociedad en México, Casa Unida de Publicaciones, México.

Bastian, Jean-Pierre

1994 Protestantismoy modernidad latinoamericana. Historia de unas minorías religiosas activas en América Latina, Fondo de Cultura Económica, México.

BAstian, JeAN-PierRe

1999 "Los nuevos partidos políticos confesionales evangélicos y su relación con el Estado en América Latina”, en Estudios Sociológicos, vol. 17, núm. 49, pp. 153-173.

BlancARTE, ROBERTO

1992 Historia de la Iglesia católica en México, Fondo de Cultura Económica, México.

BLANCARTE, ROBERTO

2016 "Discriminados discriminadores", en Milenio Diario, 7 de junio <https://www.milenio. com/opinion/roberto-blancarte/perdon-pero/ discriminados-discriminadores $>$ [7 de enero de 2019].

BLANCARTE, ROBERTO

2018 "Los ultraconservadores al poder", en Milenio Diario, 29 de mayo <https://www.milenio. com/opinion/roberto-blancarte/perdon-pero/ los-ultraconservadores-al-poder $>$ [ 7 de enero de 2019].

Cervantes-Ortiz, Leopoldo

2015 "Protestantismo entre Norte, Centro y Sudamérica. Iglesias históricas, avivamiento pentecostal, nuevas formas religiosas", en Carlos Garma y María del Rosario Ramírez Morales (coords.), Comprendiendo a los creyentes: la religión y la religiosidad en sus manifestaciones sociales, Universidad Autónoma Metropolitana-Iztapalapa/Juan Pablos Editor, México, pp. 77-98.

Cervantes-Ortiz, Leopoldo

2018 "Reacomodos coyunturales de los evangélicos en México. Elecciones y políticas públicas. 25 años de observaciones y críticas”, en Protestante Digital, 24 de mayo <http:// protestantedigital.com / cultural / 44783/ Reacomodos coyunturales de los evangelicos en_Mexico_Elecciones_y_politicas_publicas 25_anos_de_observaciones_y_criticas $>$ [7 de enero de $20 \overline{1}$ ]

Cox, Harvey

1994 Fire from Heaven, the Rise of Pentecostal Spirituality and the Reshaping of Religion, Addison Wesley, Nueva York.

Da Costa, Néstor (COORD.)

2004 Laicidad en América Latina y Europa, repensando lo religioso entre lo público y lo privado en el siglo XXI, Centro Latinoamericano de Economía Humana, Montevideo.

DOUglas, Mary

2006 El Levítico como literatura, una investigación antropológica y literaria de los ritos en el Antiguo Testamento, Gedisa, Barcelona.

Dussel, EnRIgue 1977 Religión, Edicol, México.

Galeana, Patricia (COORD.)

2001 Relaciones Estado-Iglesia. Encuentros y desencuentros, Secretaría de Gobernación-Subsecretaría de Población, Migración y Asuntos Religiosos/Archivo General de la Nación, México.
Garma, Carlos

2004 Buscando el Espíritu. Pentecostalismo en Iztapalapa y la Ciudad de México, Universidad Autónoma Metropolitana-Iztapalapa/Plaza y Valdés, México.

Garma, Carlos

2007 "Pluralismo religioso en el contexto internacional. Las controversias y polémicas con las agrupaciones", en Angela Giglia, Carlos Garma y Ana Paula de Teresa (comps.), Adónde va la antropología, Universidad Autónoma Metropolitana-Iztapalapa/Juan Pablos Editor, México, pp. 243-267.

Garma, Carlos

2008 "Las masculinidades en la música cristiana", en Versión, núm. 21, pp. 83-100.

GARMA, CARLOS

2010 "Mexico: Religious Tensions in Latin America's First Secular State", en Hemisphere, vol. 19, núm. 1, pp. 13-15.

Garma, CARlos

2011 "Laicidad, secularización y pluralismo religioso, una herencia cuestionada", en Revista del Centro de Investigación de la Universidad La Salle, vol. 9, núm. 36, pp. 79-92 <http: / /ojs.dpi.ulsa. $\mathrm{mx} /$ index.php/rci/article/view/125/329> [7 de enero de 2019].

Garma, Carlos y Blanca Leiva

2015 "Documentando la diversidad. Materiales para entender la situación actual de las religiones en México", en Carlos Garma y María del Rosario Ramírez Morales (coords.), Comprendiendo a los creyentes: la religión y la religiosidad en sus manifestaciones sociales, Universidad Autónoma Metropolitana-Iztapalapa/Juan Pablos Editor, México, pp. 99-127.

Garma, Carlos

Y RAÚl MÉNDEZ

2012 "Viva Cristo, viva Juárez. La marcha evangélica del natalicio de Juárez", en Patricia Fournier, Carlos Mondragón y Walburga Wiesheu (coords.), Peregrinaciones ayery hoy, El Colegio de México, México, pp. 181-210.

Hernández Borbolla, Manuel

2018 "AMLO se guarda en el inicio de campaña y predica sus ideas religiosas", en Huffington Post, 30 de marzo.

INEGI

2018 "Religión", en INEGI < http: / / www.beta.inegi.org. $\mathrm{mx} /$ temas/religion / $>$ [7 de enero de 2019].

JAIMES MaRTínez, RAMIRo

2007 "Neopentecostales en Tijuana", en Renée de la Torre y Cristina Gutiérrez Zúñiga (coords.), Atlas de la diversidad religiosa en México, El Colegio de la Frontera Norte / Centro de Investigaciones y Estudios Superiores en Antropología Social/Consejo Nacional de Ciencia y Tecnología/El Colegio de Michoacán/Secretaría de Gobernación-Subsecretaría de Población, Migración y Asuntos Religiosos, México, pp. 305-312

Martin, DAVID

1990 Tongues of Fire. The Explosion of Protestantism in Latin America, Basil Blackwell, Oxford.

Martínez García, Carlos

2015 "Partido Encuentro Social; hermano vota por hermano", en La Jornada, 27 de mayo < https: / / www.jornada.com.mx/2015/05/27/opinion/ O17al pol> [7 de enero de 2019]. 

Masferrer, Elio
2018 Lo religioso dentro de lo político, las elecciones de México 2018, Araucaria, Buenos Aires.

Meyer, JeAN

1989 Historia de los cristianos en América Latina, siglos XIX y XX, Vuelta, México.

Ortega Gómez, Bibiana Astrid

2018 "Partidos políticos evangélicos", en Roberto Blancarte (coord.), Diccionario de Religiones en América Latina, Fondo de Cultura Económica/ El Colegio de México, México, pp. 438-445.

Patiño Reséndiz, A.E.

2016 "Religión y poder, un estudio sobre el poder político-religioso en la comunidad evangélica. El caso de Casa sobre la Roca", tesina de maestría en Ciencias Antropológicas, Posgrado en Ciencias Antropológicas-Universidad Autóno-

PitT-Rivers, Julian ma Metropolitana-Iztapalapa, México.

1977 Antropología del honor, ensayos de antropología mediterránea, Grijalbo, Madrid.

RIFREM

2017 Encuesta Nacional sobre Creencias y Prácticas en México Encreer/Rifrem 2016, Informe de resultados, Red de Investigadores del Fenómeno Religioso en México <http://www. rifrem.mx/wp-content/uploads / 2017/10/ INFORME-DE-RESULTADOS-Encuesta NacionalMexicoCreenciasyPracticas Religiosas-2017-05.pdf $>$ [ $1^{\circ}$ de junio de 2017].

Rodríguez García, Arturo

2018 "Con referencias bíblicas. AMLO asume candidatura del Pes", en Proceso, 20 de febrero <https: / /www.proceso.com.mx/523315/conreferencias-biblicas-amlo-asume-candidaturadel-pes> [ 7 de enero de 2019].
Romero Puga, Juan Carlos

2018 "Qué haría Jesús: el voto provida y profamilia", en Letras Libres, núm. 233, pp. 12-15.

Ruiz, RubÉN

1992 Hombres nuevos. Metodismo y modernización en México (1873-1930), Casa Unida de Publicaciones, México.

ScotT, Lindy "LuIs"

1991 Salt of the Earth, a Socio-Political History of Mexico City Evangelical Protestants (19641991), Casa Unida de Publicaciones, México.

ToRre, RENÉE DE LA

y CRIstina GutiérRez ZúÑiga (COORDS.)

2007 Atlas de la diversidad religiosa en México, El Colegio de la Frontera Norte/Centro de Investigaciones y Estudios Superiores en Antropología Social/Consejo Nacional de Ciencia y Tecnología/El Colegio de Michoacán/ Secretaría de Gobernación-Subsecretaría de Población, Migración y Asuntos Religiosos, México.

VARELA, ROBERTO

1996 "Los estudios recientes sobre la cultura política en la antropología social mexicana”, en Esteban Krotz (coord.), El estudio de la cultura política en México (perspectivas disciplinarias $y$ actores políticos), Consejo Nacional para la Cultura y las Artes / Centro de Investigaciones y Estudios Superiores en Antropología Social, México, pp. 200-239.

VÁZgueZ, FELIPE

1991 Protestantismo en Xalapa, Gobierno del Estado

Weber, Max de Veracruz, Xalapa.

1983 Economía y sociedad, Fondo de Cultura Económica, México. 